\title{
EDITORIAL
}

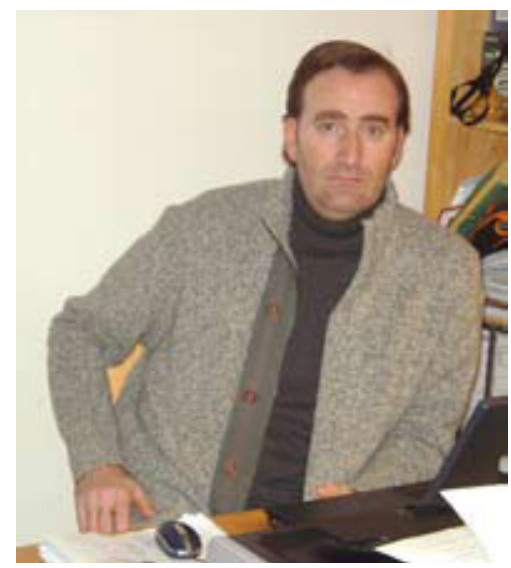

Ángel Jesús Callejón Ferre

Doctor Ingeniero Agrónomo en el programa de doctorado Biología, Ecología

y Productividad de los Vegetales de la

Universidad de Almería, España

Doctor por la Universidad de Almería en el programa de doctorado Ingeniería Ambiental, España

Especialista en Evaluación de Impacto Ambiental y Auditoría Ambiental por la Universidad Politécnica de Madrid, España Profesor del Departamento de Ingeniería Rural de la Universidad de Almería, España

\section{LA BIOMASA PROCEDENTE DE CULTIVOS AGRARIOS: ENERGÍA RENOVABLE}

Dados los tiempos que corren en los que el precio de los combustibles fósiles va en aumento, donde los países productores de petróleo enmascaran sus reservas reales y capacidades de producción, en los que surgen muy serias dudas sobre la seguridad en el uso de la energía nuclear, y donde las emisiones de dióxido de carbono $\left(\mathrm{CO}_{2}\right)$, metano $\left(\mathrm{CH}_{4}\right)$ y óxido nitroso $\left(\mathrm{N}_{2} \mathrm{O}\right)$, entre otros, van a la baja por los acuerdos internacionales entre países, la Unión Europea ha establecido unos objetivos ambiciosos para las energías renovables (ER) obligando a sus países miembros a aumentar un $20 \%$ el uso de ER desde el 2010 hasta el año 2020.

En este contexto, la necesidad de uso de energías alternativas inagotables, sostenibles y respetuosas con el medio ambiente agudiza el ingenio de millones de personas en todos los ámbitos de la ciencia. Las investigaciones se centran sobre la energía hidráulica, energía eólica, energía geotérmica, energía solar y biomasa, es decir, las consideradas energías renovables. De todas ellas, se espera que la biomasa ocupe un puesto bastante relevante, sobre todo, en los sistemas agropecuarios y forestales.

En el sector agrario habría que diferenciar entre biomasa procedente de restos de cosechas y biomasa procedente de cultivos energéticos. La primera, y objeto fundamental de este editorial, sería el "residuo vegetal" sobrante tras la vida útil (obtención de frutos para alimentación) del cultivo y la segunda sería la consecuencia del cultivo industrial sin otro fin que su uso para obtener energía bien directamente o mediante transformación del producto vegetal. Ambas biomasas, con o sin transformación físico/química, podrían destinarse a uso energético y por lo tanto se les podría denominar biocombustibles. Entre estos últimos destacan leñas y astillas, carbón vegetal, pelets y briquetas, bioetanol y biometanol, metilester y dimetilester, aceites piroleñosos, biogás, gas obtenido por gasificación y biohidrógeno. 
La biomasa generada por el sector agropecuario puede ser una fuente de recursos económicos para los habitantes de países subdesarrollados (más recursos), en desarrollo (más empleo) y desarrollados (menos uso energía fósil) además de mejorar el control de residuos, el reciclaje de nutrientes, la creación de empleo, el suministro eléctrico de zonas rurales, la gestión de tierras y la reducción de contaminación de $\mathrm{CO}_{2}$, esto último como consecuencia de que durante el crecimiento de las plantas se absorbe el dióxido de carbono que posteriormente será emitido en su combustión (efecto neutro). No obstante, los expertos aconsejan sólo realizar la combustión en último lugar y agotados todos los posibles usos viables y respetuosos con el entorno. Así, desde un punto de vista más ambiental, con los residuos procedentes de cultivos agrarios lo mejor sería clasificarlos, reciclarlos y reutilizarlos. Un ejemplo claro de este hecho sería el heno destinado para alimentación animal o la transformación de restos vegetales en compost vegetal.

Hasta ahora en el sector agrario de muchos países no existe un estudio exhaustivo de la biomasa generada, aunque sí es cierto que países como los "Países Bajos", entre otros, tienen bases de datos en las que se almacenan cantidades inmensas de información (www.phyllis.nl). El reto sería poder inventariar por países este tipo de recurso (diferenciando por especies vegetales). El inventario o ficha de cada especie debería tener como mínimo datos sobre análisis proximal (cenizas, componentes volátiles y carbono fijo), análisis elemental (C, H, N, S y O), análisis orgánico (lignina, celulosa y hemicelulosa), cantidad de cloro, composición de las cenizas, fusibilidad de las cenizas y poder calorífico. Igualmente, los datos deberían difundirse a nivel mundial.

Como ejemplo, en Almería (Sureste de España) se producen alrededor de un millón de toneladas de residuo vegetal procedente de los cultivos hortofrutícolas de invernadero (tomate, pepino, pimiento, calabacín, melón, sandía, berenjena y judía) que hasta fechas recientes no han sido estudiados de forma meticulosa. Los estudios han caracterizado la biomasa y en función de los resultados obtenidos esta podrá ser utilizada para diferentes aprovechamientos energéticos o no. Pero esto sólo es un análisis puro y duro del material vegetal y habría que seguir investigando sobre los problemas logísticos, sobre todo en lo referente a la recogida y distribución de restos vegetales. Estos abandonan la explotación con la siguiente composición:

- Mezcla de diversas partes del vegetal (raíces, tallos y hojas).

- Anillas de polietileno para tutorar las plantas. Por cada planta aparecen 4 o 5 anillas.

- Hilos de polietileno (rafia) en dos formatos, cinta y cordón. Por cada mata aparece un hilo.

- Una cierta cantidad de frutos que no se han recolectado de las plantas al finalizar la cosecha.

- Tierra adherida a las raíces de las plantas.

- Trozos de alambre procedentes de la estructura del invernadero.

- Otros restos plásticos.

Lo que se pretende advertir es que quizás es más importante conocer y resolver las dificultades técnicas de extracción del material vegetal, su manipulación y transporte, que los datos físico-químicos obtenidos por análisis en laboratorio.

Todos estos hechos encarecen las operaciones de obtención y abastecimiento, teniendo además que homogeneizar el material utilizable, lo que implica fuertes inversiones económicas para el aprovechamiento de biomasa.

Por otro lado, los componentes inorgánicos de la biomasa pueden causar problemas de contaminación en sus emisiones de combustión. Además, el K, Na, S, P, Ca, Mg, Fe y principalmente el $\mathrm{Cl}$, están involucrados en el deterioro de los hornos o calderas de combustión.

Evidentemente, la biomasa puede tener limitaciones en sus aplicaciones energéticas debido a su composición química y propiedades físicas variables (según su procedencia) y a la inseguridad de abastecimiento de las futuras plantas de energía, pero lo que sí está claro que técnicamente su aprovechamiento energético, cuando no quede más remedio, es posible, pero ¿A qué precio? 